\title{
MODO DE CONHECIMENTO ESTÉTICO E MUNDO EM SCHOPENHAUER
}

Jair BARBOZA ${ }^{1}$

- RESUMO: O presente texto intenta mostrar que o modo de conhecimento estético em Schopenhauer funciona como um poder de crítica à racionalidade instrumental da ciência regida pelo princípio de razão.

- PALAVRAS-CHAVE: Schopenhauer; sujeito do conhecimento; princípio de razão; modo de conhecimento estético.

\section{I}

A frase de abertura da obra magna de Schopenhauer, O Mundo como Vontade e como Representação, soa: "o mundo é minha representação". Para o autor, esta é uma verdade válida para qualquer ser que vive e conhece, embora só o homem possa trazê-la à consciência refletida e abstrata. Fazendo-o, aparece a clarividência filosófica, com o que se torna claro que não se conhece sol algum, terra alguma, mas aí sempre é um olho que vê o sol, é uma mão que toca a terra etc. O mundo existe tão-somente como objeto em relação ao sujeito, intuição de quem intui, "numa palavra, representação". Uma verdade que o autor identifica nas considerações céticas das quais partiu Descartes e em Berkeley, que a formulou explicitamente no seu célebre "ser é ser percebido".

Schopenhauer, assim, ao render o seu tributo ao cogito cartesiano e ao idealismo berkeleyano, parte em sua teoria do conhecimento da represen-

1 Professor Adjunto do Departamento de Filosofia e do Programa de Pós-Graduação em Filosofia da Pontifícia Universidade Católica do Paraná-PUC-PR. Artigo recebido em set/06 e aprovado para publicação em nov/06. 
tação como primeiro fato, Tatsache, da consciência. Todavia, a forma primeira e essencial da representação é a divisão em sujeito e objeto, a forma do objeto sendo o princípio de razão, que reza que "nada é sem uma razão pela qual é". Este princípio explica as coisas que nos aparecem, procura um fundamento, Grund para elas, porém não é passível de explicação alguma, tal exigência já pressupondo a validade do princípio. Procurar prova para o princípio de razão, diz o filósofo, denota ausência de clareza de consciência, pois quem exige uma prova para ele, exige um fundamento, e assim já o toma como verdadeiro, caindo no círculo que exige a prova do direito de exigir uma prova

Ora, se em $O$ mundo... o princípio de razão é a forma do objeto, cabe perguntar o que, por sua vez, é esse objeto? A resposta: ser-objeto significa ser conhecido por um sujeito. Por seu turno, ser-sujeito significa ter um objeto. "Tais metades são, em conseqüência, inseparáveis, mesmo para o pensamento: cada uma delas possui significação e existência apenas por e para a outra; cada uma existe com a outra e desaparece com ela. Elas se limitam imediatamente: onde começa o objeto, termina o sujeito" (Schopenhauer, 2005, p.46).

Analisar o conceito de sujeito leva necessariamente ao conceito de objeto, e vice-versa. Trata-se de uma ligação analítica entre os dois termos. O sujeito, porém, não se confunde com o princípio de razão. Aquele que tudo conhece não é ele mesmo objeto de conhecimento. O sujeito é o "sustentáculo do mundo", a condição universal e sempre pressuposta de tudo o que aparece, pois tudo o que existe, existe para o sujeito; contudo, ocorre com o sujeito o mesmo que com o olho, que tudo vê, mas não é visto. Isto porque o sujeito atua em cada entendimento que representa, encontra-se em cada corpo animal, em cada indivíduo, que são plurais, situados no tempo e no espaço, mas o sujeito ele mesmo não se encontra fragmentado em nenhuma dessas formas, que, antes, já o pressupõem via princípio de razão. O sujeito do conhecer é uno e indivisível.

Aquele que tudo conhece mas não é conhecido por ninguém é o SUJEITO. Este é, por conseguinte, o sustentáculo do mundo, a condição universal e sempre pressuposta de tudo o que aparece, de todo objeto, pois tudo o que existe, existe para o sujeito. Cada um encontra-se a si mesmo como esse sujeito, todavia, somente na medida em que conhece, não na medida em que é objeto do conhecimento.... O sujeito, entretanto, aquele que conhece e nunca é conhecido, não se encontra nessas formas, que, antes, já o pressupõem. Ao sujeito, portanto, não cabe pluralidade nem seu oposto, unidade. Nunca o conhecemos, mas ele é justamente o que conhece, onde quer que haja conhecimento. (Schopenhauer, 2005, pp.45-6)

Ao dizer que o mundo é representação do sujeito, Schopenhauer segue os passos deixados por Kant na Crítica da razão pura, na qual é afirmado 
que só podemos conhecer aparências (fenômenos; Erscheinungen), não as coisas em si mesmas. Todo conhecimento se dá quando dados externos são fornecidos à sensibilidade, ou receptividade do conhecimento, em suas formas a priori do espaço e do tempo. Em seguida, o entendimento, ou espontaneidade do conhecimento, com doze categorias radicadas nele a priori pensa os dados da sensibilidade. De modo que, do concurso entre sensibilidade e entendimento tem-se o conhecimento dos fenômenos. Daí a célebre frase da primeira crítica: "Pensamentos sem intuição são vazios, intuições sem conceitos são cegas" (Kant, 1998, p.130). O entendimento não intui, a sensibilidade não pensa. Só do concurso de ambos surge o conhecimento, que, sublinha Kant, refere-se exclusivamente à experiência fenomênica possível. A coisa-em-si permanece um "x" desconhecido, mero objeto de pensamento, o limite do conhecimento científico. Aqui encontrando-se a sentença de morte da metafísica dogmática, com suas pretensões de conhecer o incondicionado: Deus, mundo, imortalidade da alma. Entre nós e o em-si sempre haverá o entendimento e a sensibilidade, limitando-nos assim à finitude, ao conhecimento dos objetos condicionados a aparecerem na cadeia necessária de causa e efeito. Mas, embora o mundo da experiência seja formado de fenômenos, isso não significa que aquilo que aparece seja mera fantasmagoria, porque senão, conclui Kant, haveria uma aparência sem algo que aparecesse, haveria, pode-se assim dizer, causas sensíveis sem a sua causalidade inteligível, justamente o em-si.

\section{II}

Ora, Schopenhauer segue os passos de Kant, e na sua teoria da representação, exposta no primeiro livro de sua obra magna, considera que a representação do indivíduo não passa de fenômeno formado com os dados da sensibilidade. A coisa-em-si mesma é inacessível à mera intuição empírica. Porém, o filósofo opera uma mudança no kantismo. Sensibilidade e entendimento não são nitidamente separados. O entendimento abriga em si apenas uma categoria, a de causalidade, e não doze, como em Kant. A economia agora feita encontra justificativa no próprio Kant, pois este, todas as vezes que fornece um exemplo rigoroso de operação das categorias, sempre recorre à causalidade; por sua vez, as formas da sensibilidade, espaço e tempo, são alocadas no próprio entendimento, ao lado da causalidade, que os vincula. Neste sentido, tempo, espaço e causalidade, doravante nomeadas princípio de razão do devir, apreendem os dados empíricos fornecidos pela sensibilidade corpórea e constituem a natureza. O entendimento intui diretamente, adquire um caráter sensível e, quando as sensações lhe são fornecidas, as toma como um efeito, para, via causalidade, remontar tempo- 
ralmente até a sua origem, posicionando-as no espaço como representação intuitiva, objeto empírico constituído, figura. A causalidade, ao vincular espaço e tempo no entendimento, possibilita portanto a percepção (intuição empírica) do mundo, já que a própria matéria não passa de causalidade: o seu ser é o seu fazer-efeito, wirken, e a realidade seria mais apropriadamente chamada de efetividade, Wirklichkeit, ou seja, um fazer-efeito do sujeito que a representa. Um termo, para o idealismo do autor, muito mais apropriado na designação do mundo concreto que o latino "realidade". Portanto, toda intuição é intelectual. provas disto são dadas pelo fato de a visão invertida dos objetos ser endireitada pelo entendimento; pelo fato de, quando se coloca a cabeça por entre as pernas, isso não acarreta a inversão do mundo, mas ele aparece como se o víssemos em posição correta; ou então o fato de os dois olhos verem mas percebermos apenas um objeto etc.

Por conseguinte, o mundo como representação possui duas metades essenciais, necessárias e inseparáveis: uma é o objeto, o fenômeno apreendido pelo princípio de razão e pluralizado ao infinito, a outra é o sujeito, que não se encontra no espaço nem no tempo, pois está por inteiro e indiviso em cada ser que representa. "Por conseguinte, um único ser que representa, com o objeto, complementa o mundo como representação tão integralmente quanto um milhão deles. Contudo, caso aquele único ser desaparecesse, então o mundo como representação não mais existiria" (Schopenhauer, 2005, p.46).

\section{III}

Tendo-se em mente essa concepção da origem da representação, exposta no primeiro livro de $O$ mundo como vontade e como representação, pode-se pensar que Schopenhauer circunscreve a validade do princípio de razão, como forma necessária e universal do objeto, às formas apriorísticas do entendimento usadas na experiência do mundo. Porém, ao se consultar A quádrupla raiz do princípio de razão suficiente, texto que o filósofo aconselha como introdução à sua obra principal, verifica-se que espaço, tempo e causalidade indicam apenas uma figura do princípio de razão, a do devir. "Devir" porque se trata da construção dos objetos da efetividade, em constante mudança. Entretanto, na mesma Quádrupla raiz... são indicadas mais outras três figuras do princípio de razão que, ao lado da figura do devir, referem-se ao "quádruplo" do título da obra. Trata-se de um único princípio porém quadruplamente enraizado, isto é, dando conta de quatro diferentes classes de objeto para o sujeito, classes estas que delimitam o mundo da experiência e da ciência. 
O mundo fenomênico e as formas a priori de fundamentação que o possibilitam, pode, pois, ser visto de quatro perspectivas diferentes. A primeira é a do princípio de razão do devir, do próprio entendimento que intui fenômenos, como vimos. Depois se tem: princípio de razão do conhecer, que rege a classe de representações abstratas, ou seja, os conceitos formados a partir das intuições do entendimento; conceitos estes a caberem exclusivamente ao homem, embora os animais tenham em comum conosco o entendimento; em verdade, a razão decanta as intuições e obtém representações de representações, exatamente os conceitos, os quais, ligados entre si, formam juízos, que, se possuem fundamento suficiente, são verdadeiros. O princípio de razão do conhecer, em última instância, fornece o fundamento dos juízos da experiência e da ciência; rege a linguagem e a sua pretensão de expressar verdadeiramente o mundo.

Há ainda o princípio de razão de ser, que rege a terceira classe de objetos para o sujeito, a parte formal das representações, as intuições a priori das formas do sentido externo e interno, isto é, o espaço e o tempo, que, como vimos, formam, ao lado da causalidade, o princípio de razão do devir. Neste contexto, espaço e tempo são tomados isoladamente, sem referência à sua aplicação às intuições. De tais formas resultam leis que traduzem a necessidade e a universalidade da aritmética e da geometria. Assim, o fundamento de ser no tempo, portanto na aritmética, diz que no tempo cada momento é condicionado pelo anterior, cada número pressupõe o antecedente como seu fundamento suficiente e por conta disso, sabe-se que onde há o número 10 também há 8, 6, 4, etc. Já o fundamento de ser no espaço, portanto a geometria, permite a intelecção da natureza das figuras em seus limites recíprocos, bem como a construção isolada de cada uma. O espaço é a possibilidade de determinações de suas partes entre si, o que se chama posição. O espaço é secundário em relação ao tempo, pois este é a forma primária do ser-consciente, é a forma do sentido interno, onde o sentido do mundo se constitui. Isto se traduz nas vezes em que a própria geometria precisa ser temporalizada e suas figuras são traduzidas em fórmulas numéricas.

Por fim, princípio de razão do agir, que rege a quarta classe de objetos para o sujeito. Em realidade, não se trata aqui de objeto em sentido estrito, mas do sujeito tornado objeto, o sujeito do querer, que não pode ser representado. Neste caso, está-se diante daquilo que Schopenhauer denomina "milagre" do conhecimento - o eu. O eu é uma mistura de conhecer e querer, dois elementos completamente distintos. Aqui, observando a si mesmo, o investigador se apreende no íntimo de seu corpo como um sujeito que quer. De fato, diz o filósofo, quando submergimos em nosso interior, encontramo-nos como pura volição irrompendo em diversos graus, a envolverem afetos e sentimentos. Concomitantemente, mostra-se neste momento que as regras entre sujeito e objeto, que valiam para as outras figuras do princí- 
pio de razão, não valem mais aqui, pois neste caso se tem algo que não pode ser tomado como objeto no sentido estrito do termo, ou seja, como representação - justamente a vontade. Isso não impede Schopenhauer de indicar, mesmo nesse domínio, que a volição de cada um está na base da sua ação, pois esta possui um fundamento suficiente, motivos determinantes, condutores do sujeito do querer. Há, portanto, uma lei de motivação e esta, em última instância, é o princípio de razão do agir.

O que se tem nesse traçado da quádrupla raiz do princípio de razão é uma geografia da finitude, na qual cada domínio tem a sua legislação e uma não interfere na outra. Neste ponto, um explorador dessa geografia seria talvez levado à conclusão de que Schopenhauer, após afirmar que o sujeito do conhecimento conhece mas não é conhecido, e que a forma do objeto é o princípio de razão, agora, pelas portas do fundo, introduz uma pluralização do sujeito, antes dito uno. Noutros termos, a cada uma das classes de objeto regidas por uma figura do princípio de razão corresponderiam quatro tipos de sujeito, pois o objeto existe sempre para o sujeito; só que o princípio de razão não é pensável sem o sujeito, logo, sujeito e princípio de razão se confundiriam. Mas isso Schopenhauer quer evitar. Ele se mantém fiel à concepção de que o sujeito do conhecimento é uno e indiviso, pois não está no espaço nem no tempo, mas, nestes, encontram-se apenas os indivíduos com seus entendimentos, sejam humanos ou animais. De modo que, se o sujeito do conhecimento é único, e ainda assim há quatro figuras do princípio de razão, tais figuras devem ser interpretadas antes como quatro poderes cognitivos do sujeito, mediante os quais ele conhece a partir do indivíduo. Tais poderes dão conta da finitude, sem que o sujeito entre na finitude como objeto dela, vale dizer, o sujeito do conhecimento não se temporaliza, não se confunde com o mundo, em verdade, ele é o olho que vê o mundo, é pois o limite do mundo e do que pode ser dito e traçado sobre ele. Desta perspectiva os animais, por terem entendimento, portanto conhecerem intuitivamente, também indicam a presença neles do sujeito do conhecimento.

\section{IV}

Por conta da quádrupla raiz do princípio de razão e sobretudo devido ao processo de construção das representações intuitivas, depreende-se que a frase de abertura da obra máxima de Schopenhauer não deve ser tomada em sentido literal. Não existe correspondência imediata entre a minha representação e o mundo representado. A representação em mim é, antes de tudo, uma complexa atividade no interior do cérebro, ao fim da qual se tem uma imagem. O próprio representado está envolto em incertezas, é fenômeno, e este é fundamentalmente regido pelo tempo como "forma arquetípica" 
da finitude, que torna tudo heraclitianamente passageiro, irreal, transitório. Cada momento dele é um parricida: só subsiste se aniquila o momento anterior, para ser então aniquilado pelo momento posterior. O princípio de razão é o Véu de Maia posto entre o sujeito que conhece e os objetos conhecidos, obstando a visão nítida deles, como eles são em em-si mesmos. Essa irrealidade leva o filósofo a identificar a vida com o sonho e a citar os poetas que se debruçaram sobre tal temática. A vida é sonho, e os sonhos, sonhos são, já dizia Calderon de la Barca em A Vida é Sonho. Já em Píndaro o homem é o sonho de uma sombra; para Sófocles, em Ájax, "nada somos senão figuras ilusórias, imagens de sombras fugidias."; e Shakespeare, em A Tempestade, diz que "somos feitos do mesmo estofo que os sonhos e a nossa breve vida está rodeada de um sono."

O fenômeno, por conseguinte, para Schopenhauer, não tem consistência. Vida e sonho são folhas de um único e mesmo livro. A leitura encadeada se chama vida real; quando, porém, finda a hora de leitura habitual - o dia - e chega o tempo de descanso e recuperação, ainda folheamos, diz o filósofo, com freqüência descontraídos, sem ordem e encadeamento uma folha ora aqui, ora ali. Muitas vezes se trata de uma folha já lida, outras de uma desconhecida, mas sempre folhas do mesmo livro. Uma folha lida assim isoladamente se encontra de fato fora do encadeamento com a leitura consistente do livro. Todavia, não temos aí algo de muito discrepante, caso se pense que também o todo da leitura consistente começa e termina do mesmo modo, ao sabor do momento, e, por isso, pode ser visto meramente como uma grande folha isolada no livro lido por um leitor cósmico. Embora os sonhos isolados se separem da vida real pelo fato de não intervirem no encadeamento da experiência (que transcorre com constância pela vida) e o despertar indique essa diferença, o encadeamento que pertence à vida real como sua forma também pertence ao sonho. Caso se tome o ponto de vista do julgamento exterior a ambos, não se encontra em sua essência nenhuma diferença mais determinada, e é-se obrigado a conceder aos poetas que a vida é um sonho.

\section{V}

Só que, para além dos fenômenos, e aqui Schopenhauer resgata uma realidade para além do sonho, pode-se encontrar outro tipo de representação, independente do princípio de razão e que, em verdade, é o núcleo dos objetos. Trata-se das Idéias. O conhecimento destas não se liga mais ao indivíduo, mas aí se isola o objeto da torrente fugidia dos fenômenos, daquela ilusão onírica que os envolve e, por um corte vertical na horizontalidade fe- 
nomênica, é-se elevado à sua espécie, ao seu arquétipo. Nesse instante desaparecem o indivíduo e o princípio de razão. O sujeito contempla puramente os arquétipos da natureza e se desfaz neles. Há uma identidade sujeito-objeto. O conhecimento destemporaliza-se e atinge o que há de mais nuclear nas coisas. De modo privilegiado isso ocorre na arte, "exposição de Idéias".

Importante aqui é sublinhar que aquele sujeito da teoria do conhecimento, uno e indiviso nos fenômenos, é o que agora, puramente, correlaciona-se com as representações independentes do princípio da razão. Nesse "estado estético", estabelecido por uma "ocasião externa" ou uma "disposição interna", ocorre uma supressão da individualidade e de "um só golpe" puro sujeito do conhecimento e Idéia ocupam a consciência, expulsando desta o princípio de razão e seu correlato, o fenômeno. O puro sujeito do conhecimento cessa por momentos de ver turvadamente pela finitude, pelo tempo, e passa a ver sub specie aeterni, do ponto de vista da eternidade. Desaparecem os limites tão marcantes entre sujeito e objeto quando da consideração empírica da natureza. A gente, diz Schopenhauer, "se perde" completamente no objeto, esquece da própria individualidade e permanece como puro sujeito, "claro espelho do objeto", não se podendo mais separar aquele que intui, da intuição. O que é conhecido nesse instante não é a coisa isolada, o fenômeno, mas a sua Idéia; não o seu "como" (onde, por que, para que) mas o seu "quê". O olho que vê não é o de um particular, mas o "claro olho cósmico". Todo o poder do espírito é "devotado à intuição e nos afunda por completo" nela. A consciência inteira é preenchida pela calma contemplação do objeto: um quadro, uma paisagem, uma árvore, um penhasco, uma construção ou outra coisa qualquer .

O sujeito do conhecimento, portanto, livra-se do princípio de razão, da finitude que turva a sua visão cristalina e considera o próprio conteúdo do princípio de razão, dos fenômenos. Fá-lo na bela natureza ou na bela arte.

No fundo, tem-se nessa intuição estética um modo de conhecimento que se contrapõe ao científico, que segue sempre o princípio de razão, enquanto o modo estético é independente do princípio de razão. Aquele segue a torrente infinda de fundamento a conseqüência; de cada fim alcançado é remetido a outro, sem nunca alcançar um repouso, "tão pouco quanto, correndo, pode-se alcançar o ponto onde as nuvens tocam a linha do horizonte"; é um modo de conhecimento instrumental e racional a serviço das vontade e dos interesses humanos, que torna a natureza um objeto de manipulação para satisfazer desejos os mais variados e muitas vezes estranhos e gratuitos. Já o modo de conhecimento estético, independente do princípio de razão, faz a pessoa desinteressar-se pelo objeto, num estado de pura contemplação. É o modo de conhecimento que vale nas artes e na fruição 
da natureza, ao retirar o objeto considerado da torrente fugidia da necessidade fenomênica e isolá-lo como representante de sua espécie. "A roda do tempo pára. As relações desaparecem". Permanece apenas o essencial das coisas. É indiferente os olhos de quem vê, se de um mendigo ou de um rei. É indiferente o lugar de onde se contempla, se um castelo ou uma prisão.

Quem se absorve em tal estado estético pode depois, com uma técnica escolhida, comunicar sua vivência em forma de obra de arte e assim emprestar seus olhos aos espectador.

Podemos, por conseguinte, definir a arte COMO O MODO DE CONSIDERAÇÃO DAS COISAS INDEPENDENTE DO PRINCÍPIO DE RAZÃO, oposto justamente à consideração que o segue, que é o caminho da experiência e da ciência. Este último tipo de consideração é comparável a uma linha infinita que corre horizontalmente; o primeiro, por sua vez, a uma linha vertical que corta a outra linha num ponto qualquer. O modo de consideração que segue o princípio de razão é o racional, único que vale e ajuda na vida prática e na ciência; já o modo que prescinde do conteúdo deste princípio é o genial, único que vale e ajuda na arte. O primeiro é o modo de consideração de Aristóteles, o segundo é no todo o de Platão. (Schopenhauer, 2005, p.254)

Pode-se, por conseguinte, concluir dessas linhas o poder crítico da estética schopenhauereana à soberania do logos científico, pois o que Schopenhauer aponta é que há outro modo de conhecer o mundo, que não segue necessariamente a razão, mas a intuição estética e que, em termos metafísicos, satisfaz mais a quem conhece pois é um modo que opera um corte vertical na cadeia horizontal dos objetos condicionados, tornando-se uma "decifração do enigma do mundo". É uma intuição que atravessa o Véu de Maia dos fenômenos e deixa o espectador ver o íntimo da natureza, logo, o "quê" do "como" do mundo; indizível nele mesmo, mas que se mostra na experiência do belo ao claro olho cósmico. Trata-se aí ao mesmo tempo do olhar místico para o cosmo, de uma experiência de totalidade que não pode ser negada por todos aqueles que se aprofundaram na fruição do belo, de forma que a racionalidade científica é colocada em claros limites em suas pretensões de dizer o sentido do mundo. O sentido do mundo é indizível, é inefável, apreensível apenas na experiência mística, que não pode ser comunicada, nem mesmo pelo filósofo, mas somente vivenciada. No fundo, o filósofo nos interroga sobre se de fato alguma vez experienciamos em toda a sua magnitude uma autêntica obra da arte ou da natureza. Se o fizemos, sabemos que o enigma do mundo não se resolve pelo princípio de razão, mas numa mirada unitotal e não verbalizável do claro olho cósmico. 
BARBOZA, J. Way of aesthetic knowledge and world in Schopenhauer. Trans/Form/ Ação, (São Paulo), v.29(2), 2006, p.33-42.

- ABSTRACT: This text aims to show that the way of aesthetic knowledge in Schopenhauer functions as a critic to the instrumetnal rationality of the science under the regency of the principle of suffciente reason.

- KEYWORDS: Schopenhauer; knowing subject; principle of suffciente reason; way of aesthetic knowledge.

\section{Referências bibliográficas}

KANT. Kritik der reinen Vernunft. Hamburg: Felix Meiner, 1998.

SCHOPENHAUER. O mundo como vontade e como representação. Trad. Jair Barboza. São Paulo: EdUnesp, 2005.

Werke in fünf Bänden. Zurique: Haffmans, 1988. 